\title{
Una nueva especie de Liolaemus (Iguania: Liolaemidae) perteneciente al grupo L. montanus en las lomas costeras del sur de Perú
}

\author{
Luis Villegas Paredes ${ }^{1,2}$, Ling Huamaní-Valderrama² ${ }^{2}$ César Luque-Fernández ${ }^{1,2}$,
} Roberto Carlos Gutiérrez ${ }^{3}$ 4* $^{*}$, Aarón Josué Quiróz ${ }^{3}$ \& Cristian Simón Abdala ${ }^{5}$

1. Instituto de Ciencia y Gestión Ambiental de la Universidad Nacional de San Agustín de Arequipa, Perú (ICIGAUNSA); chungungo_lvp@hotmail.com, cluquef@gmail.com

2. Laboratorio de Ecología, Sección de Ecología y Conservación, Facultad de Ciencias Biológicas, Universidad Nacional de San Agustín de Arequipa. Perú; lingdorishuamanivalderrama@gmail.com

3. Museo de Historia Natural, Universidad Nacional de San Agustín de Arequipa, Perú; salamanqueja@gmail.com, aaronjosue21@hotmail.com

4. Servicio Nacional de Áreas Naturales Protegidas por el Estado - Perú.

5. CONICET - Unidad Ejecutora Lillo (UEL) - Facultad de Ciencias Naturales e IML, Universidad Nacional de Tucumán, Argentina; samiryjazmin@gmail.com

* Correspondencia

Recibido 16-IV-2019. Corregido 02-XII-2019. Aceptado 10-I-2020.

\begin{abstract}
A new species of Liolaemus (Iguania: Liolaemidae) of the group L. montanus from the coastal hills of Southern Peru. The genus Liolaemus presents great diversity among the current tetrapods. It is the second genus with the highest number of valid species described of the Iguana infraorder. In this study, we described a new species of sand lizard from the coastal lomas of Quilca, La Chira and Ocoña that belongs to the subgenus Eulaemus and group of Liolaemus montanus, all in the province of Camaná, department of Arequipa, Peru. To determine the taxonomic status of this new organism, we analyzed morphological, molecular and geographical characters. The morphological characters allowed the characterization and diagnosis of the new species, the molecular data was used to make a Bayesian inference, and the geographic data served to determine potential distribution areas. This lizard diverges from the other species of the Liolaemus montanus group for its small to medium size, several sets of morphological characters, folidosis and color pattern. It is also the only species of the genus where the males have a pattern of lateral spots of rounded shape with dark border and green interior, from the armpits to the middle of the body. Additionally, the molecular phylogenetic results made with the Cyt-b gene indicate that it has no direct relationship with the phenetically similar species described for the group; nevertheless, there is a relationship with geographically close populations, which has not been properly described. Finally, it was determined that this lizard has a very marked endemism and its populations are not abundant.
\end{abstract}

Key words: lizard, taxonomy, desert, Camaná, Arequipa.

Villegas Paredes, L., Huamaní-Valderrama, L., Luque-Fernández, C., Gutiérrez, R.C., Quiróz, A.J., \& Abdala, C. S. (2020). Una nueva especie de Liolaemus (Iguania: Liolaemidae) perteneciente al grupo L. montanus en las lomas costeras del sur de Perú. Revista de Biología Tropical, 68(1), 69-86.

Hasta la fecha se han descrito alrededor de 270 especies del género Liolaemus (Abdala \& Quinteros, 2014; Gutiérrez et al., 2018; Uetz, 2019). Dentro del género se reconocen dos subgéneros: Eulaemus y Liolaemus "sensu stricto". A su vez, dentro de estos se reconocen grupos divididos en varios subgrupos, incluido el grupo de L. montanus (Abdala, Acosta, Cabrera, Villavicencio, \& Marinero, 2009; Abdala \& Juárez-Heredia, 2013; Abdala \& Quinteros, 2014). Actualmente, en Perú se conocen 21 especies de este género, de las 
cuales 13 pertenecen al grupo antes mencionado (Gutiérrez et al., 2018). Particularmente, en el departamento de Arequipa se conocen solo cinco especies de Liolaemus (Cei \& Péfaur, 1982; Villegas, 1990; Laurent, 1998; Aguilar, Wood, Belk, Duff, \& Sites, 2017). Sin embargo, este número podría incrementarse con más investigaciones en la zona, debido a la falta de conocimiento de la biodiversidad (Zeballos, López, Villegas, Jiménez, \& Gutiérrez, 2002; Gutiérrez, Villegas, López, \& Quiroz, 2010; Valladares, 2011; Gutiérrez et al., 2018).

Actualmente, en Perú se han descrito las siguientes especies: Liolaemus annectens, Liolaemus etheridgei, Liolaemus insolitus y Liolaemus tacnae en el departamento de Arequipa; Liolaemus williamsi, Liolaemus polystictus, Liolaemus melanogaster, y Liolaemus wari en el departamento de Ayacucho; Liolaemus signifer en el departamento de Puno. La mayoría de estos organismos pertenecen al grupo de Liolaemus montanus, con excepción de L. tacnae, $L$. walkeri y $L$. wari, las cuales pertenecen a los subgrupos L. alticolor - bibroni y L. ornatus del grupo L. boulengeri (Etheridge, 1995; Abdala, 2007; Lobo, Espinoza, \& Quinteros, 2010; Quinteros, 2012; Quinteros, 2013; Aguilar et al., 2013; Abdala \& Quinteros, 2014).

Teniendo lo anterior en cuenta, la lagartija que describiremos es asignada al grupo de Liolaemus montanus por presentar las sinapomorfias propuestas por Etheridge (1995) para este grupo, particularmente una hipertrofia del músculo tibialis anticus (Abdala, Abdala, \& Tulli, 2006), originada por un proceso posterior distal de la tibia en forma de navaja. En general, del total de especies del grupo de Liolaemus montanus conocidas en el sur de Perú y norte de Chile, solo L. insolitus, L. poconchilensis y $L$. reichei se distribuyen en zonas costeras en alturas menores a los 1000 m.s.n.m. (Valladares, 2004; Gutiérrez et al., 2018; ValladaresFaundez, Etheridge, \& Simón-Abdala, 2018).

Aunque estas últimas son fenéticamente similares con la especie que se describe en este trabajo, los análisis moleculares indican que no hay relación cercana. Asimismo, existen unas formas aún no descritas de Liolaemus para la zona de Nazca en el departamento de Ica, y en el norte del departamento de Arequipa (Aguilar et al., 2017), las cuales también difieren molecularmente de la nueva especie. De igual manera, la nueva especie de Liolaemus, posee una combinación de caracteres que lo distinguen del resto de los Liolaemus descritos.

A fin de poner a prueba la hipótesis que le dé validez a la especie que se describe en este trabajo, utilizamos el concepto general o unificado de especie. Este lo define como entidades que representan linajes históricos independientes o linajes divergentes de meta-poblaciones (De Queiroz, 1998). Nuestro criterio operacional para inferir el límite entre especies está basado en la elaboración de árboles filogenéticos moleculares y la caracterización morfológica, al igual que otras descripciones de nuevos Liolaemus (Ávila et al., 2017).

\section{MATERIALES Y MÉTODOS}

Características morfológicas: La descripción se basa en especímenes depositados en las colecciones herpetológicas del Museo de Historia Natural de la Universidad Nacional de San Agustín de Arequipa (MUSA, Arequipa, Perú), en el Museo de Historia Natural de la Universidad Mayor de San Marcos (MUSM, Lima, Perú) y en el Museo de Biodiversidad del Perú (MUBI; Cusco, Perú). Se revisaron un total de 18 ejemplares para la obtención de la descripción de la especie propuesta desde las instalaciones del Museo de Historia Natural de la Universidad Nacional de San Agustín de Arequipa. Los ejemplares estaban fijados en formol al $10 \%$ y preservados en etanol al $70 \%$. Las coordenadas del sitio de recolecta fueron tomadas con un GPS Garmín eTrex. Mientras tanto, los datos georreferenciados para la preparación del mapa se manejaron con el programa QGIS (QGIS Development Team, 2017).

En general, los caracteres descritos fueron los comúnmente utilizados para Liolaemus citados por Laurent (1986), Villegas (1990), Lobo y Espinoza (1999), Pincheira-Donoso y Núñez (2005), Abdala (2007), Abdala y Juárez-Heredia (2013). Las medidas fueron 
tomadas en gabinete con un calibrador digital de precisión $0.01 \mathrm{~mm}$. Los conteos y observaciones de escamas fueron realizados a través de un estereoscopio con magnificación 4X. Mientras tanto, la descripción de coloración fue realizada en los organismos vivos en campo y con ayuda de fotografías. La terminología del patrón de coloración del cuerpo sigue a Lobo y Espinoza (1999) y Abdala (2007).

Extracción de ADN, PCR, secuenciación y alineamiento de secuencias: Las muestras de tejido muscular fueron obtenidas de lagartijas fijadas en etanol al $96 \%$. Para la extracción de DNA, se utilizó el Kit IBI C (Larson, 2015) siguiendo el protocolo del fabricante. El gen mitocondrial Cyt-b fue amplificado a partir del ADN total extraído utilizando los primers IguaCytob F2 (5'-CCACCGTTGTTATTCAACTAC-3') e IguaCytob R2 (5'-GGTTTACAAGACCAATGCTTT-3'). Las condiciones del PCR fueron las siguientes: 94 ${ }^{\circ} \mathrm{C}$ durante cinco min luego de 35 ciclos; $94{ }^{\circ} \mathrm{C}$ durante $30 \mathrm{~s} ; 50{ }^{\circ} \mathrm{C}$ durante $30 \mathrm{~s} ; 72{ }^{\circ} \mathrm{C}$ durante $90 \mathrm{~s}$; y finalmente $72{ }^{\circ} \mathrm{C}$ durante cinco min (Corl, Davis, Kuchta, Comendant, \& Sinervo, 2010; Aguilar et al., 2017).

Posteriormente, los amplicones fueron secuenciados por MACROGEN - USA.

Para este proceso, las condiciones del PCR fueron las siguientes: $5 \mathrm{~min}$ de precalentamiento a $94{ }^{\circ} \mathrm{C} ; 35$ ciclos por $30 \mathrm{~s}$ de desnaturalización a $94{ }^{\circ} \mathrm{C} ; 30 \mathrm{~s}$ de hibridación a 50 ${ }^{\circ} \mathrm{C}$; $90 \mathrm{~s}$ de elongación a $72{ }^{\circ} \mathrm{C}$; finalmente, se le adicionó $5 \mathrm{~min}$ de extensión final a $72{ }^{\circ} \mathrm{C}$ (Corl et al., 2010; Aguilar et al., 2017). Los amplicones obtenidos fueron secuenciados por la empresa MACROGEN - USA.
Análisis filogenético: Las secuencias obtenidas (Tabla 1) fueron comparadas con las secuencias homólogas reportadas en el GENBANK (Tabla 2) mediante la herramienta BLAST (http://blast.ncbi.nlm.nih.gov/Blast), según lo sugerido por Molina, Barreto \& Giraldo (2014). Se consideraron principalmente las especies del género registradas para el departamento de Arequipa y la zona sur del Perú y utilizadas en los últimos estudios Aguilar et al. (2017). Las 48 secuencias nucleotídicas usadas en este análisis fueron alineadas usando la extensión MUSCLE (Edgar, 2004) del programa MESQUITE versión $3.2^{\circ}$ (Maddison \& Maddison, 2017). Por otro lado, la elección del mejor modelo de evolución de nucleótidos fue realizada en el programa JModelTest Version 2.1.4 ()" (Darriba, Taboada, Doallo, \& Posada, 2012), considerando los índices de BIC y AIC.

Por su parte, el análisis de inferencia bayesiana (IB) fue corrida en Mr. Bayes v.3.2.6 ${ }^{\mathbb{C}}$ " (Huelsenbeck \& Ronquist, 2001). Todos los anteriores se realizaron dos veces durante diez millones de generaciones cada uno. Se obtuvo una desviación estándar promedio final de las frecuencias divididas por debajo de 0.05 , muestreando árboles cada 1000 generaciones y utilizando cuatro cadenas simultáneas (una fría y tres calientes) en cada ejecución. Las convergencias de las cadenas a la distribución estacionaria se confirmaron utilizando Tracer v1.6 (Rambaut, Suchard, Xie, \& Drummond, 2014) y se descartaron los primeros mil árboles muestreados que no estaban dentro de la distribución estacionaria de las probabilidades de registro. Los árboles y las probabilidades posteriores se resumieron utilizando el método de consenso de la "mayoría del 50

TABLA 1

Secuencias obtenidas de los organismos mediante la técnica PCR y posterior secuenciación

TABLE 1

Sequences obtained from organisms using the PCR technique and sequencing

\begin{tabular}{ccc} 
Especie & Voucher & GenBank \\
Liolaemus balagueri sp. nov. & MUSA 5578 & MK568538 \\
Liolaemus balagueri sp. nov. & MUSA 5575 & MK568539 \\
\hline
\end{tabular}


TABLA 2

Secuencias homólogas obtenidas en GenBank para realizar comparación

TABLE 2

Homologous sequences obtained in GenBank for comparison purposes

\begin{tabular}{|c|c|c|}
\hline Especie & Voucher & GenBank \\
\hline L. ornatus & MUSM31438 & KX826632.1 \\
\hline L. poconchilensis & MUSM31545 & KX826637.1 \\
\hline L. insolitus & MUSM31490 & KX826627.1 \\
\hline L. insolitus & BYU50462 & KX826626.1 \\
\hline L. ortizi & MUSM 31514 & KX826634.1 \\
\hline L. ortizi & MUSM 31513 & KX826633.1 \\
\hline L. thomasi & BYU50469 & KX826680.1 \\
\hline L. thomasi & MUSM31516 & KX826681.1 \\
\hline L. williamsi & MUSM31485 & KX826687.1 \\
\hline L. williamsi & BYU50464 & KX826685.1 \\
\hline L. williamsi & BYU50463 & KX826684.1 \\
\hline L. williamsi & BYU50143 & KX826682.1 \\
\hline L. melanogaster & MUSM31472 & KX826630.1 \\
\hline L. melanogaster & BYU50151 & KX826628.1 \\
\hline L. sp. Abratoccto & MUSM31468 & KX826672.1 \\
\hline L. sp. Abratoccto & BYU50431 & KX826664.1 \\
\hline L. sp. Abratoccto & MUSM31465 & KX826671.1 \\
\hline L. sp. Abratoccto & MUSM31374 & KX826667.1 \\
\hline L. sp. Abratoccto & MUSM31371 & KX826665.1 \\
\hline L. sp. Abratoccto & MUSM31481 & KX826660.1 \\
\hline L. sp. AbraApacheta & BYU50148 & KX826659.1 \\
\hline L. sp. AbraApacheta & BYU50145 & KX826658.1 \\
\hline L. polystictus & MUSM31451 & KX826642.1 \\
\hline L. polystictus & MUSM31446 & KX826641.1 \\
\hline L. robustus & MUSM31508 & KX826648.1 \\
\hline L. robustus & MUSM31505 & KX826647.1 \\
\hline L. robustus & BYU50483 & KX826643.1 \\
\hline L. robustus & MUSM31504 & KX826646.1 \\
\hline L. signifer & MUSM31447 & KX826657.1 \\
\hline L. signifer & MUSM31434 & KX826654.1 \\
\hline L. signifer & BYU50357 & KX826651.1 \\
\hline L. signifer & BYU50350 & KX826649.1 \\
\hline L. signifer & BYU50355 & KX826650.1 \\
\hline L. signifer & MUSM31443 & KX826656.1 \\
\hline L. signifer & BYU50444 & KX826652.1 \\
\hline L. signifer & MUSM31437 & KX826655.1 \\
\hline L. signifer & MUSM29110 & KX826653.1 \\
\hline L. etheridgei & BYU50497 & KX826662.1 \\
\hline L. etheridgei & BYU50494 & KX826620.1 \\
\hline L. etheridgei & BYU50495 & KX826621.1 \\
\hline L. annectens & BYU50491 & KX826617.1 \\
\hline L. annectens & BYU50486 & KX826615.1 \\
\hline L. annectens & BYU50489 & KX826616.1 \\
\hline L. sp. Nazca & MUSM31524 & KX826677.1 \\
\hline L. sp. Nazca & MUSM31523 & KX826676.1 \\
\hline L. sp. Nazca & BYU50472 & KX826673.1 \\
\hline L. sp. Nazca & BYU50508 & KX826675.1 \\
\hline L. sp. Nazca & BYU50507 & KX826674.1 \\
\hline
\end{tabular}

\%"(Huelsabeck \& Ronquist, 2001; Wilcox, Zwickl, \& Heath, 2002).

Establecimiento de la distribución potencial y hábitat: Para la determinación del área de distribución potencial de la especie de estudio, se realizó el modelado de nicho ecológico a partir de variables ambientales y los registros de presencia de las especies. En cuanto a las variables ambientales, se utilizaron las 19 del programa Worldclim (Fick \& Hijmans, 2017). También se emplearon variables adicionales como radiación solar, índices de vegetación (NDVI) y mapa de cobertura vegetal, las cuales fueron construidas a una resolución de $100 \mathrm{~m}$.

Previamente, se realizó un análisis de correlación entre las variables por utilizar en el modelo con la herramienta NicheToolBox (Osorio-Olvera, 2016), la cual se ejecuta bajo la plataforma de R (R Core Team, 2016) que, asimismo, integra el software de modelación de máxima entropía - MAXENT (Phillips, Anderson, \& Shapire, 2006). Los resultados para el modelo fueron evaluados utilizando medidas de desempeño sobre los valores de AUC (área bajo la curva ROC) con valores entre 0.5 (no diferencia del azar) a uno (puntuación mejor que el azar; Fielding \& Bell 1997). Además, se realizó una evaluación de las variables más importantes para determinar cuál de estas predice mejor el nicho fundamental de la especie, para lo cual se utilizaron valores de AUC entre cero (no importante) y uno (importante).

\section{RESULTADOS}

Liolaemus balagueri sp. nov. (Tabla 3, 4 y 5; Figs. 2 y 3 )

Análisis filogenético: El análisis de inferencia bayesiana se fundamenta en un data set final compuesto por 45 muestras de especies del grupo Liolaemus montanus, 2 muestras de la nueva especie y 1 muestra de $L$. ornatus del grupo "boulengeri" como "outgroup". Se tuvo como modelo de evolución nucleotídica GTR + $\mathrm{G}+\mathrm{I}$. Esta filogenia bayesiana (Fig. 1) muestra 


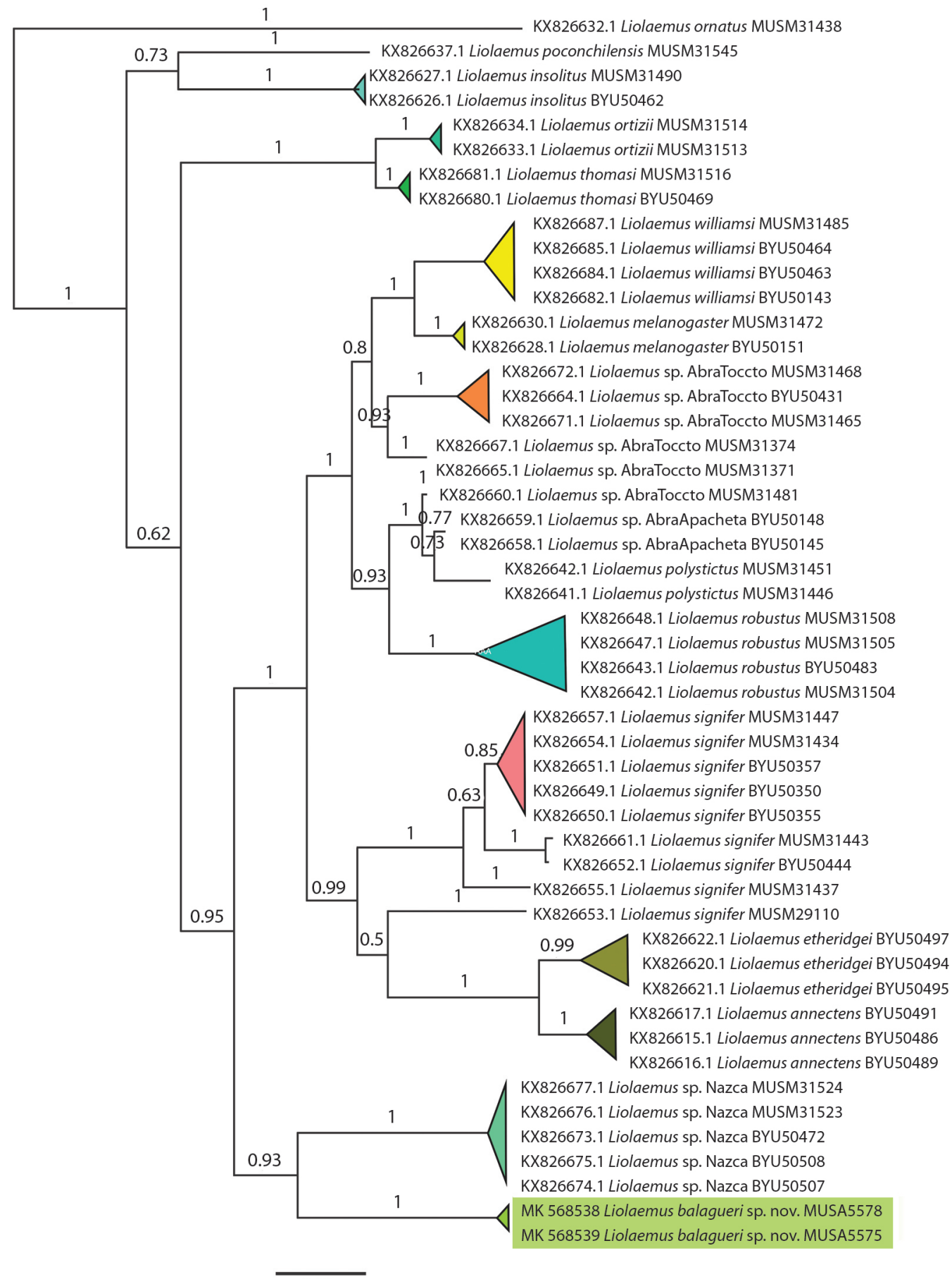

0.03

Fig. 1. Árbol filogenético del grupo de L. montanus, incluido Liolaemus balagueri sp. nov. (MUSA 5575, MUSA 5578). Fig. 1. Phylogenetic tree of the L. montanus group, including Liolaemus balagueri sp. nov. (MUSA 5575, MUSA 5578). 


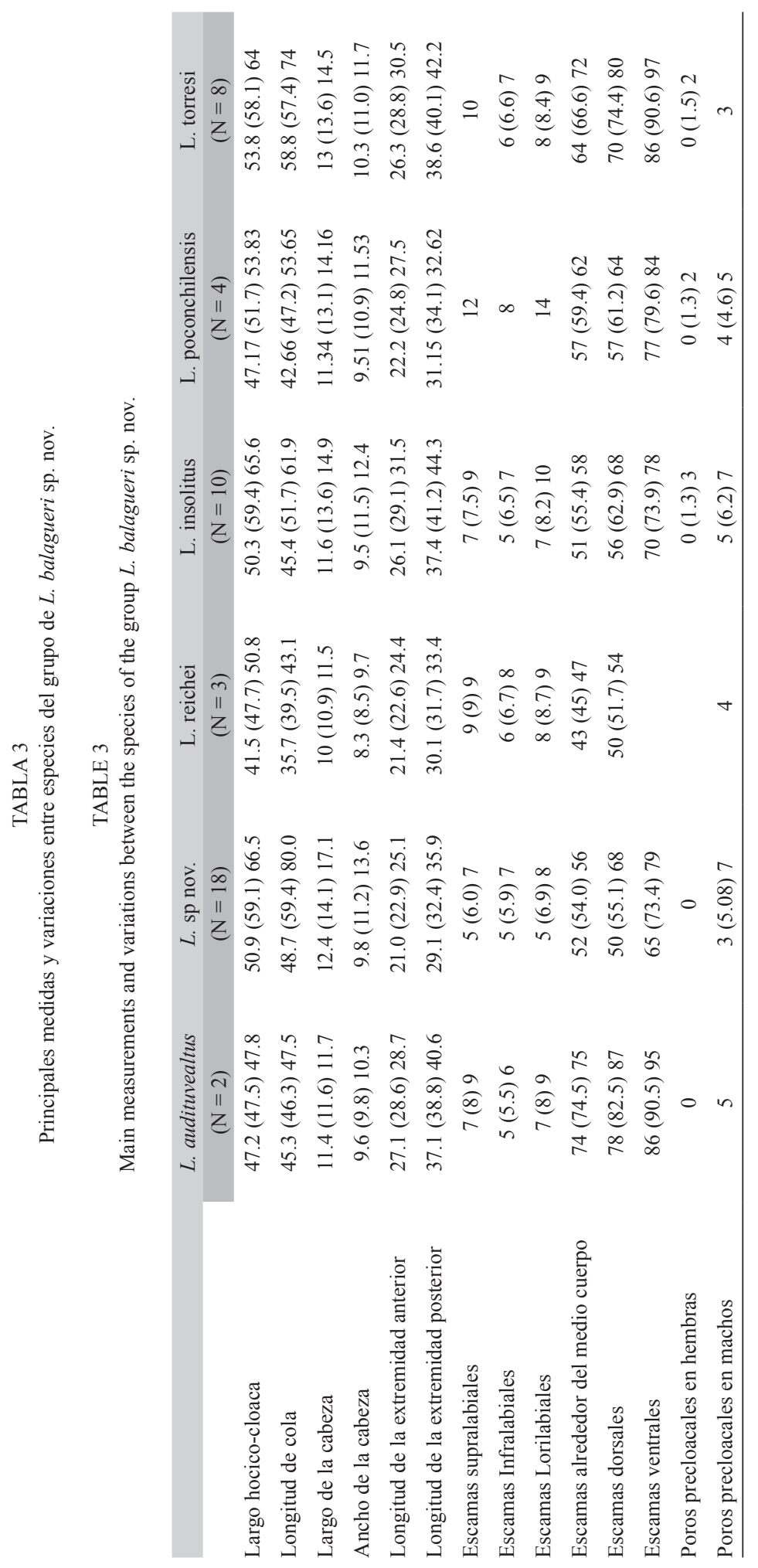




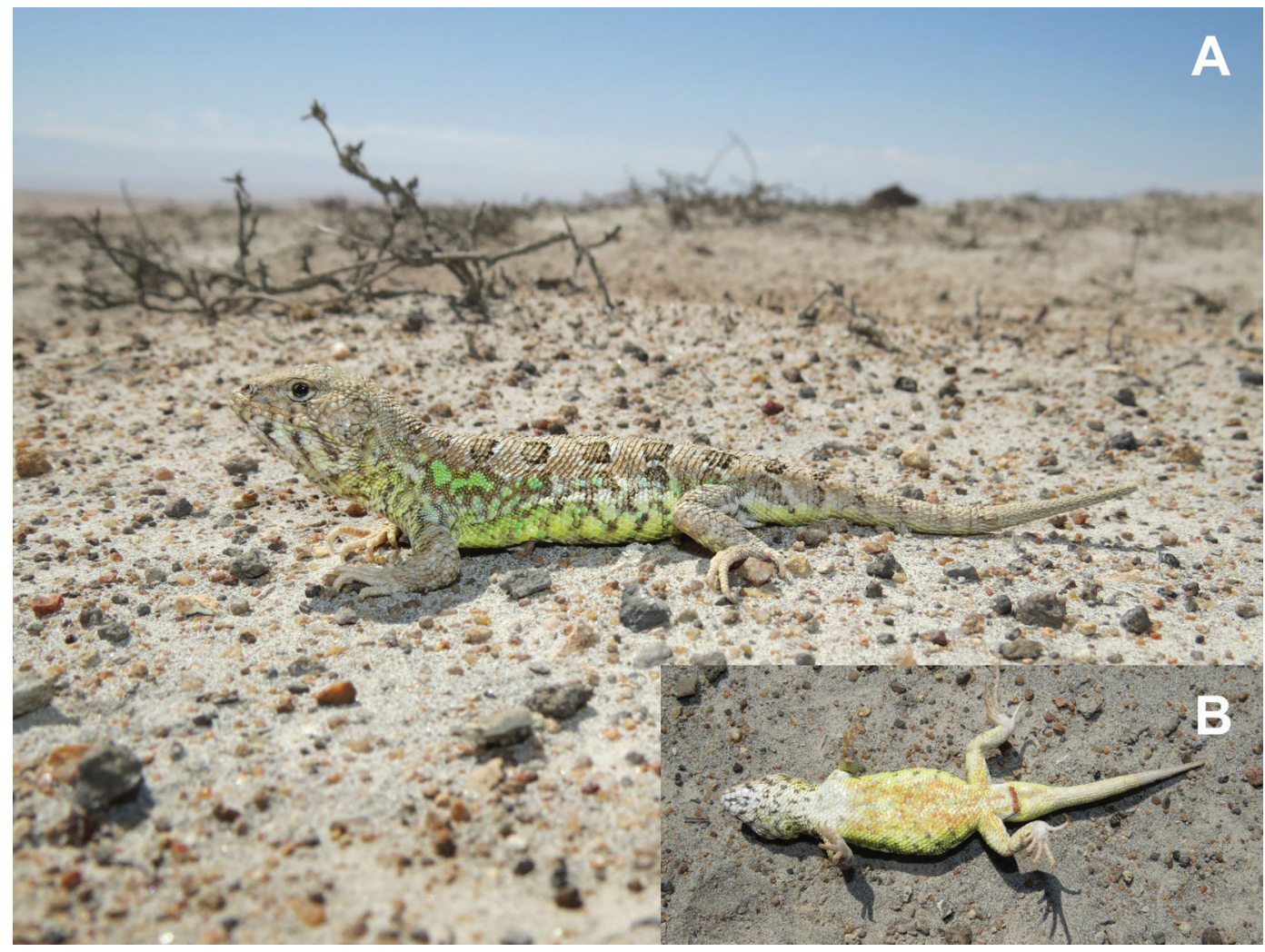

Fig. 2. A. Vista lateral de un macho adulto de Liolaemus balagueri sp. nov. en su hábitat natural. B. Vista ventral del mismo ejemplar.

Fig. 2. A. Side view of a male adult of Liolaemus balagueri sp. nov. in the natural habitat. B. Ventral view of the same specimen.

a la especie descrita, Liolaemus balagueri sp. nov. (MUSA 5575, MUSA 5578), como clado monofilético $(\mathrm{pp}=1)$, taxón hermano de la población de Liolaemus sp. en Nazca ( $\mathrm{pp}=1)$. Además, separa a Liolaemus balagueri sp. nov. de las poblaciones de L. insolitus y L. poconchilensis - a pesar de su similitud fenética - así como de las demás poblaciones altoandinas de Liolaemus. Por tanto, se considera que $L$. balagueri sp. nov. es una especie diferente a las anteriormente descritas para el grupo de $L$. "montanus" (pp = 1).

Análisis morfológico: Las diferencias morfológicas entre las poblaciones analizadas y el resto de las especies de Liolaemus, están plasmadas en el diagnóstico de la nueva especie y se detallan en la Tabla 3.

La combinación de caracteres de lepidosis, las medidas morfométricas $\mathrm{y}$, principalmente, el patrón de coloración de machos y hembras, nos permiten realizar un diagnóstico claro y fundamentado. Además, aporta evidencia suficiente a favor de la descripción de esta nueva especie para la ciencia. En las Fig. 2A, Fig. 2B y Fig. 3A, Fig. 3B se pueden apreciar las vistas frontales y laterales de los machos esta especie (Liolaemus balagueri sp. nov.) y las hembras paratipo.

Holotipo: Se trató de un macho adulto (MUSA 5575) recolectado a $3.17 \mathrm{~km}$, al oeste de la carretera Majes - Camaná antes de llegar 


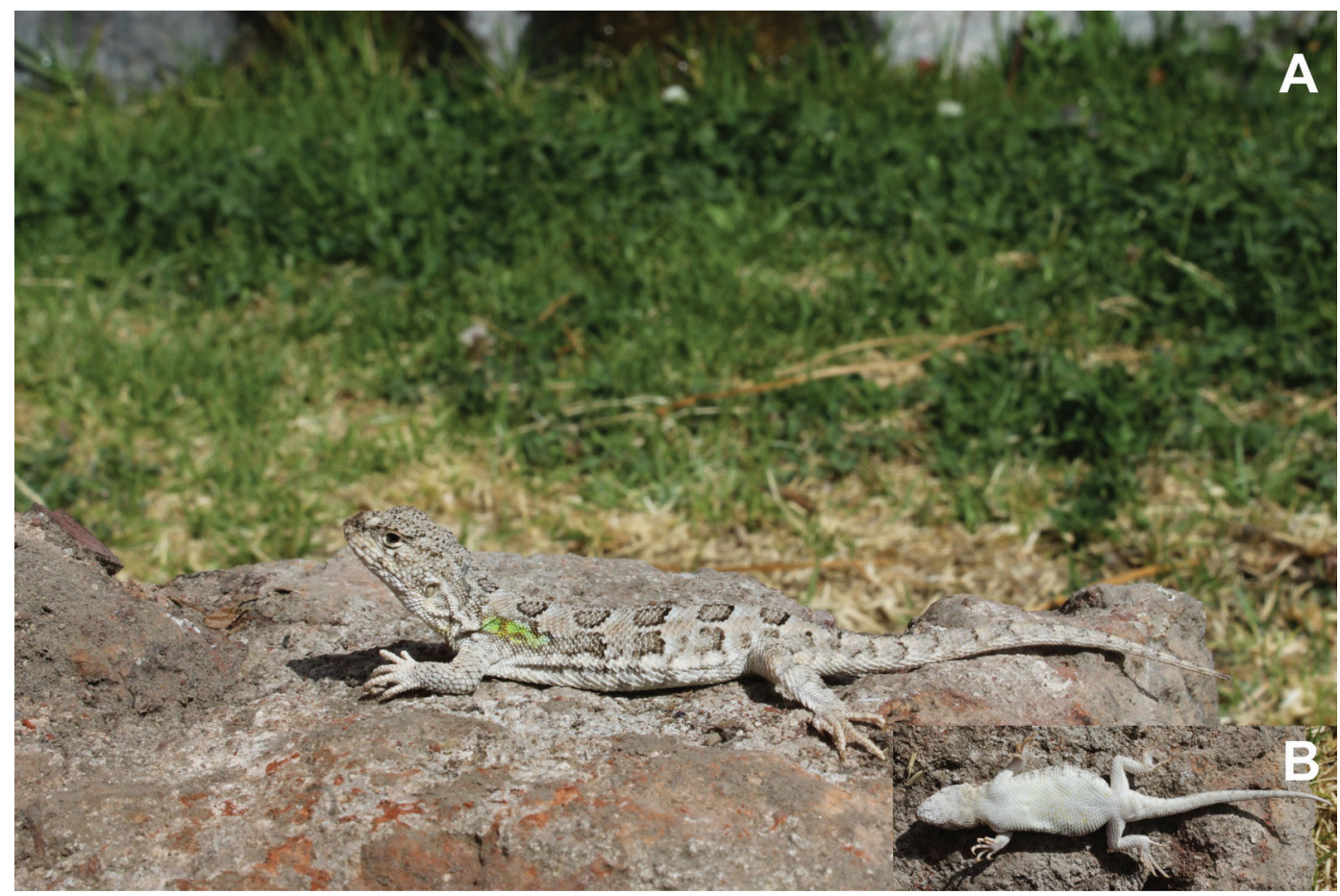

Fig. 3. A. Ejemplar paratipo hembra (MUSA 5578) en vista lateral. B. Vista ventral del mismo ejemplar Fig. 3. A. Side view of the female paratype (MUSA 5578) in side view. B. Ventral view of the same specimen.

a la quebrada del Toro $\left(16^{\circ} 34^{\prime} 23.94\right.$ ' S \& $72^{\circ} 33^{\circ} 43.02^{\prime \prime}$ W) a $1058 \mathrm{~m}$ de altitud, Distrito de Quilca, Provincia Camaná, Departamento de Arequipa, Perú. Fue almacenado por Luis Villegas, Ling Huamaní y César Luque el 23 de julio 2017.

Paratipos: Se emplearon tres machos (MUBI 13206, MUSA 1772 - 1773) y cuatro hembras (MUSA 1774, MUBI 13207-13209), recolectados en la misma localidad del holotipo en las coordenadas $16^{\circ} 34^{\prime} 23^{\prime \prime} \mathrm{S} \&$ \& $72^{\circ} 33^{\prime} 43^{\prime \prime}$ W por Roberto Gutiérrez, Aarón Quiroz y Luis Villegas el 11 de agosto de 2010. Un macho (MUSM 39195) fue recolectado en la misma localidad que el holotipo, particularmente las coordenadas $16^{\circ} 34^{\prime} 11.96 " \mathrm{~S} \&$ \& $72^{\circ} 34^{\prime} 00.53^{\prime \prime}$ W por César Luque, Luis Villegas y Anthony Pauca el 02 de abril del 2017. Asimismo, otro macho (MUBI 16483) fue recolectado en la misma localidad que el holotipo en las coordenadas 16³4'19.21" S \& 72³3'53.95” W por
Luis Villegas, Ling Huamaní y Cesar Luque el 02 de abril de 2017.

De la misma manera, cinco machos (MUSA 5576-5577, MUBI 16484, MUSM 39193-39194) fueron recolectados en la misma localidad que el holotipo por Luis Villegas, Ling Huamaní y César Luque el 23 de julio de 2017, así como una hembra (MUSA 5578) recolectada por Luis Villegas, Ling Huamaní y César Luque el 08 de septiembre de 2017. En las lomas de La Chira, Distrito de Camaná, Provincia de Camaná en el departamento de Arequipa, se recolectaron dos machos (MUSA 5579 y MUSM 39192) por Luis Villegas, César Luque, Raquel Ruiz y Anthony Pauca, el 16 de diciembre de 2017.

Diagnóstico: La especie identificada fue asignada al grupo o serie de Liolaemus montanus (Etheridge, 1995; Schulte, Macey, Espinoza, \& Larson, 2000) porque presenta un proceso posterior distal en la tibia - en forma 
de navaja - asociado a la hipertrofia del músculo tibialis anticus (Etheridge, 1995; Abdala, Abdala, \& Tulli, 2006). Fue denominada como Liolaemus balagueri sp. nov. Dentro de la serie o grupo de L. montanus, se diferencia de las especies del grupo de L. boulengeri (Abdala, 2007; Schulte et al., 2000) por tener escamas de igual tamaño en la parte posterior del muslo. Por un lado, en L. montanus, se diferencia de L. annectens, L. aymararum, L. cazianiae, L. chlorostictus, L. dorbignyi, L. fabiani, L. filiorum, L. forsteri, L. foxi, L. gracielae, $L$. huayra, L. huacahuasicus, L. igneus, L. inti, L. jamesi, L. juanortizi, L. melanogaster, L. montanus, L. multicolor, L. nigriceps, L. orientalis, L. pantherinus, L. pachecoi, L. patriciaiturrae, L. pleopholis, L. polystictus, L. puritamensis, L. robustus, L. scrocchii, L. signifer, L. tacora, L. thomasi, L. vulcanus, L. vallecurensis, y $L$. williamsi por ser especies de mayor tamaño. Por ejemplo, el LHC de L. balagueri sp. nov. oscila entre 66.50 y $75 \mathrm{~mm}$.

Por otro lado, se diferencia de L. andinus, L. audituvelatus, L. cazianiae, L. chlorostictus, L. eleodori, L. erguetae, L. fabiani, L. forsteri, L. foxi, L. gracielae, L. halonastes, L. insolitus, L. islugensis, L. jamesi, L. molinai, L. manueli, L. nigriceps, L. omorfi, L. patriciaiturrae, $L$. pleopholis, L. poconchilensis, L. poecilochromus, L. porosus, L. reichei, L. robertoi, $L$. rosenmanni, L. ruibali, L. schmidti, L. scrocchii, L. tacora, L. torresi, L. vallecurensis y L. vulcanus porque tienen escamas dorsales del cuerpo yuxtapuestas y sin quilla, escamas con disposición subimbricada y presencia de una leve quilla. Estos caracteres particulares también lo diferencian de $L$. aymararum, $L$. disjunctus, L. etheridgei, L. fittkaui, L. griseus, L. huacahuasicus, L. montanus, L. orko, L. ortizi, L. pulcherrimus, L. signifer, L. thomasi y L. williamsi que tienen las escamas imbricadas $\mathrm{y}$ con quilla evidente.

El número de escamas alrededor del cuerpo en Liolaemus balagueri sp. nov., varía entre 52 y $56(=54.3)$, carácter que lo diferencia las especies del grupo que tienen más de 60 escamas, como L. andinus, L. audituvelatus, L. cazianiae, L. chlorostictus; L. duellmani,
L. eleodori, L. erguetae, L. forsteri, L. foxi, L. gracielae, L. griseus, L. halonastes, $L$. inti, L. islugensis, L. manueli, L. molinai, L. multicolor, L. nigriceps, L. orientalis, L. orko, L. ortizi, L. patriciaiturrae, L. pleopholis, L. poconchilensis, L. poecilochromus, L. polystictus, L. porosus, L. pulcherrimus, L. robustus, $L$. robertoi, L. rosenmanni, L. ruibali, L. signifer, L. torresi, L. schmidti, L. vallecurensis y de $L$. reichei que tiene menos de 50 escamas alrededor del cuerpo.

El número de escamas ventrales entre la mental y el borde de la cloaca en la nueva especie varía entre 65 y $79 \mathrm{~mm}(=72.4)$. El mayor tamaño se ha identificado en L. ortizi (53-65 $\mathrm{mm},=61.1)$. También, esto lo diferencia de otras especies que tienen más de 80 escamas ventrales como $L$. andinus, $L$. annectens, $L$. audituvelatus, $L$. cazianiae, $L$. chlorostictus, $L$. eleodori, L. erguetae, L. foxi, L. gracielae, L. hajeki, L. halonastes, L. huayra, L. inti, L. islugensis, L. multicolor, L. nigriceps, L. pachecoi, L. patriciaiturrae, L. pleopholis, L. poecilochromus, L. porosus, L. robertoi, L. rosenmanni, L. signifer, L. torresi y L. vallecurensis.

En general, la combinación de los estados de caracteres presentes en el patrón de coloración dorsal y ventral lo diferencian claramente de todas las especies del grupo de L. montanus. Sobresale particularmente el patrón de coloración dorsal y sus grandes manchas paravertebrales y laterales de forma circular o de ocelos, con borde oscuro evidente y centro claro o verde. Estos caracteres son únicos en todo el género (Fig. 2A, Fig. 2B, Fig. 3A, Fig. 3B).

Diagnosis: This species is assigned to the group or series called L. montanus (Etheridge, 1995; Schulte, Macey, Espinoza, \& Larson, 2000) because it presents a posterior distal process in the tibia (in the form of a knife) associated with the hypertrophy of the tibialis anticus muscle anticus (Etheridge, 1995; Abdala, Abdala, \& Tulli, 2006). Within this group, it differs from the species L. boulengeri (Abdala, 2007; Schulte et al., 2000) for having scales of the same size on the back of the thigh. Within the overall group, it differs in size (they are 
larger) from $L$. annectens, $L$. aymararum, $L$. cazianiae, L. chlorostictus, L. dorbignyi, $L$. fabiani, L. filiorum, L. forsteri, L. foxi, L. gracielae, L. huayra, L. huacahuasicus, L. igneus, L. inti, L. jamesi, L. juanortizi, L. melanogaster, L. montanus, L. multicolor, L. nigriceps, L. orientalis, L. pantherinus, L. pachecoi, L. patriciaiturrae, L. pleopholis, L. polystictus, L. puritamensis, L. robustus, L. scrocchii, $L$. signifer, L. tacora, L. thomasi, L. vulcanus, $L$. vallecurensis and L. williamsi. For example, the LHC of L. balagueri sp. nov. ranges from 66.50 to $75 \mathrm{~mm}$.

On the other hand, it differs from L. andinus, L. audituvelatus, L. cazianiae, L. chlorostictus, L. eleodori, L. erguetae, L. fabiani, L. forsteri, L. foxi, L. gracielae, L. halonastes, $L$. insolitus, L. islugensis, L. jamesi, L. molinai, L. manueli, L. nigriceps, L. omorfi, L. patriciaiturrae, L. pleopholis, L. poconchilensis, L. poecilochromus, L. porosus, L. reichei, L. robertoi, L. rosenmanni, L. ruibali, L. schmidti, L. scrocchii, L. tacora, L. torresi, L. vallecurensis and L. vulcanus in their dorsal scales of the body, which are juxtaposed and without keel; their scales with sub-imbricated arrangement and the presence of a slight keel in the new species. These particular traits also separate it from $L$. aymararum, $L$. disjunctus, $L$. etheridgei, L. fittkaui, L. griseus, L. huacahuasicus, $L$. montanus, L. orko, L. ortizi, L. pulcherrimus, L. signifer, L. thomasi and L. williamsi, which have imbricated scales and an evident keel.

The number of scales around the body in Liolaemus balagueri sp. nov. varies between 52 and $56(=54.3)$. This trait differentiates the species from the group that has more than 60 scales, which includes $L$. andinus, $L$. audituvelatus, L. cazianiae, L. chlorostictus; $L$. duellmani, L. eleodori, L. erguetae, L. forsteri, L. foxi, L. gracielae, L. griseus, L. halonastes, L. inti, L. islugensis, L. manueli, L. molinai, L. multicolor, L. nigriceps, L. orientalis, L. orko, L. ortizi, L. patriciaiturrae, L. pleopholis, $L$. poconchilensis, L. poecilochromus, L. polystictus, L. porosus, $L$. pulcherrimus, $L$. robustus, $L$. robertoi, L. rosenmanni, L. ruibali, L. signifer, L. torresi, L. schmidti, L. vallecurensis and
L. reichei. All of them have less than 50 scales around the body.

The number of ventral scales between the mental and the edge of the cloaca in varies between 65 and $79(\bar{x}=72.4)$, higher than $L$. ortizi $(53-65, \bar{x}=61.1)$. Additionally, this number of scales is lower than in species that have more than 80 ventral scales such as $L$. andinus, L. annectens, L. audituvelatus, L. cazianiae, L. chlorostictus, L. eleodori, L. erguetae, L. foxi, L. gracielae, L. hajeki, L. halonastes, $L$. huayra, L. inti, L. islugensis, L. multicolor, L. nigriceps, $L$. pachecoi, $L$. patriciaiturrae, $L$. pleopholis, L. poecilochromus, L. porosus, L. robertoi, L. rosenmanni, L. signifer, L. torresi and $L$. vallecurensis.

The combination of characteristics observed in the dorsal and ventral coloring pattern clearly differentiate it from all the species of the L. montanus group. Particularly, the dorsal coloring pattern, large paravertebral and lateral spots of circular or ocelli shape, with border dark evident and light or green center stand out. These traits are unique in the whole genus (Fig. 2A, Fig. 2B, Fig. 3A, Fig. 3B).

Descripción del holotipo: Consiste en un macho adulto (MUSA 5575). El ejemplar es de tamaño mediano (largo hocico-cloaca $=63.9$ $\mathrm{mm}$ ), figura esbelta, con la cabeza un poco más ancha que el cuello. Presenta el pliegue auricular y longitudinal. Esta zona también está compuesta de escamas granulares que se conectan a las escamas granulares de la parte dorsal en la inserción de los miembros superiores al cuerpo. El cuerpo es semicilíndrico y deprimido dorsoventralmente.

La cabeza es regular con el perfil triangular ligeramente convexo, un largo de $15.9 \mathrm{~mm}$, ancho de $13.3 \mathrm{~mm}$ y una altura de $11.6 \mathrm{~mm}$. La distancia del tronco (axila-ingle $=29.3 \mathrm{~mm}$ ) es 0.46 veces el tamaño del cuerpo y las extremidades anteriores y posteriores son relativamente cortas (23.9 y $35.2 \mathrm{~mm}$, respectivamente). $\mathrm{La}$ cola es cilíndrica, está ensanchada en la base y termina en la punta con una medida $68.2 \mathrm{~mm}$. El diámetro del ojo es de $3.4 \mathrm{~mm}$. Por otro lado, la longitud oído-ojo es de $6.5 \mathrm{~mm}$ : el oído 
elíptico presenta una altura de $2.4 \mathrm{~mm}$ y un ancho de $0.8 \mathrm{~mm}$. La distancia entre las narinas es de $4.2 \mathrm{~mm}$, el largo de la escama subocular es de $2.8 \mathrm{~mm}$ y el largo de la hilera de poros precloacales es de $4.3 \mathrm{~mm}$.

Por otra parte, la longitud del brazo corresponde a $8.2 \mathrm{~mm}$, del antebrazo $7.0 \mathrm{~mm}$ y la mano $8.7 \mathrm{~mm}$. La longitud del muslo es de $11.1 \mathrm{~mm}$, la tibia $10.1 \mathrm{~mm}$. y el pie $14.0 \mathrm{~mm}$. Las escamas del dorso son de subyuxtapuestas a subimbricadas y ligeramente quilladas no mucronadas, con pequeñas escamas granulares (heteronotos) entre ellas. Las escamas de los miembros anteriores y posteriores son imbricadas, laminares y levemente quilladas en la parte dorsal, mientras que la parte ventral no presenta quillas. Asimismo, las escamas de la cola son más quilladas que el dorso del cuerpo. Por su parte, las escamas ventrales son lisas, imbricadas y ligeramente más grandes que las dorsales.

En cuanto a la cabeza, esta es de superficie rugosa, la escama interparietal irregular está rodeada de siete escamas de distinto tamaño y las placas parietales (dos) son más notorias. La escama rostral es de forma semirectangular, dos veces más ancha $(2.4 \mathrm{~mm})$ que alta $(0.9$ $\mathrm{mm})$, la mental es semirectangular ligeramente más ancha $(2.4 \mathrm{~mm})$ que alta $(1.3 \mathrm{~mm})$. Las escamas supraoculares y frontal son un poco más grandes que las demás escamas cefálicas. Por otro lado, las escamas nasales se encuentran separadas de la rostral. Ellas también están divididas entre sí por cuatro escamas.

Se evidenció también una escama en el meato auditivo. Las escamas alrededor del medio del cuerpo son 54. Las escamas dorsales desde la línea imaginaria entre los bordes anteriores de los miembros posteriores hasta el occipucio también son 54 y las ventrales, desde la mental hasta la cloaca, son 74. Por su parte, las lamelas del cuarto dedo de la mano son 16 y las del pie 20 .

Coloración: Presenta una cabeza dorsalmente de color marrón. Su área parietal es ligeramente más oscura que el resto de la cabeza. Las escamas son supralabiales e infralabiales de color marrón claro al igual que las escamas temporales. Presenta una línea transversal de color negro en los parpados. Ventralmente, la cabeza es de color crema con semicírculos paralelos negros que rodean a la escama mental que continúa hasta el sector gular en forma de jaspeada.

El dorso del cuerpo es de color marrón claro, con presencia de manchas paravertebrales de forma redondeada y borde oscuro seguido por una mancha posterior blanca. Lateralmente, tiene por encima de la línea ventrolateral un color marrón claro con manchas laterales verdes bordeadas por un color marrón oscuro. Por debajo de la línea ventrolateral, presenta un color crema con escamas de color verde, amarillo y naranja.

Ventralmente, el cuerpo es crema, con algunas escamas amarillas, naranjas y negras en los laterales del abdomen. Los miembros anteriores y posteriores a nivel dorsal son de color marrón claro con presencia de manchas negras. Mientras tanto, a nivel ventral presenta un color de blanco a crema. Su cola es dorsalmente de color marrón claro con presencia de unión de las manchas paravertebrales; ventralmente, es color crema. Los poros precloacales tienen una coloración anaranjado intenso.

Variación: Los patrones de coloración de los paratipos MUSA 5579 y MUSM 39192 son similares al holotipo al presentar manchas de coloración naranja al costado de las paravertebrales en el dorso. Los paratipos MUSA 39194 y MUSA 5577 muestran una coloración corporal dorsal marrón claro. Las hembras, en general, presentan una coloración más tenue (Fig. 3A). Por lo cual, puede observarse un dicromatismo sexual a nivel ventral, ya que las hembras tienen el vientre de color blanco con algunas escamas amarillas (Fig. 3B).

Con respecto a las medidas corporales, se obtuvo que las hembras son ligeramente de menor tamaño, a excepción de la longitud axila-ingle (Tabla 4). La escamación varía de 1 a 2 escamas en el conteo de lepidosis de cabeza y de 1 a 4 escamas a medio cuerpo en promedio (Tabla 5), dependiendo del sexo del individuo. Los poros precloacales solo se presentan en 
TABLA 4

Principales medidas y variaciones entre hembras y machos de L. balagueri sp. nov.

(N: número de individuos, DS: desviación estándar)

TABLE 4

Main measures and variations between females and males of L. balagueri sp. nov. (N: number of individuals, DS: standard deviation)

\begin{tabular}{lcccccccc} 
& $\begin{array}{c}\text { Promedio } \\
\text { machos }\end{array}$ & $\begin{array}{c}\text { DS } \\
\text { machos }\end{array}$ & Variación & $\mathrm{N}$ & $\begin{array}{c}\text { Promedio } \\
\text { hembras }\end{array}$ & $\begin{array}{c}\text { DS } \\
\text { hembras }\end{array}$ & Variación & N \\
Largo hocico-cloaca & 61.12 & 4.42 & $(52.31-66.58)$ & 13 & 57.15 & 4.24 & $(50.99-62.7)$ & 5 \\
Largo de la cabeza & 15.12 & 1.32 & $(12.98-17.14)$ & 13 & 13.23 & 0.74 & $(12.46-14.4)$ & 5 \\
Ancho de la cabeza & 12.12 & 1.04 & $(10.35-13.66)$ & 13 & 10.32 & 0.36 & $(9.88-10.8)$ & 5 \\
Alto de la cabeza & 11.01 & 0.96 & $(9.27-12.4)$ & 13 & 9.44 & 0.49 & $(8.70-9.78)$ & 5 \\
Longitud cola & 65.85 & 10.12 & $(53.15-80)$ & 8 & 53.03 & 3.70 & $(48.78-55.6)$ & 3 \\
Base de la cola & 7.84 & 0.41 & $(7.29-8.6)$ & 13 & 7.77 & 0.51 & $(7.13-8.5)$ & 5 \\
Longitud axila- ingle & 26.35 & 2.37 & $(21.88-30.27)$ & 13 & 26.24 & 3.58 & $(20.85-30.9)$ & 5 \\
Longitud del fémur & 10.22 & 1.03 & $(8.72-12)$ & 13 & 8.90 & 0.61 & $(8.29-9.68)$ & 5 \\
Longitud de la tibia & 9.75 & 0.81 & $(8.33-11.54)$ & 13 & 7.96 & 0.74 & $(7.08-8.88)$ & 5 \\
Pie & 13.84 & 0.84 & $(12.70-15.2)$ & 13 & 13.62 & 0.72 & $(12.67-14.4)$ & 5 \\
Largo del brazo & 7.78 & 1.18 & $(6.02-10.06)$ & 13 & 7.45 & 0.44 & $(6.82-8)$ & 5 \\
Largo del antebrazo & 7.36 & 0.59 & $(6.68-8.68)$ & 13 & 6.57 & 0.48 & $(5.72-6.88)$ & 5 \\
Mano & 8.75 & 0.89 & $(7.04-10)$ & 13 & 7.87 & 0.67 & $(7.09-8.58)$ & 5 \\
Número de poros & 5.08 & 0.82 & $(3.00-7)$ & & 0 & & 0 & 5 \\
\hline
\end{tabular}

machos, mientras que los poros supernumerarios se presentan en ambos sexos al borde superior e inferior de la cloaca.

Etimología: Dedicamos el nombre científico al Dr. Luis Balaguer Núñez (1964-2014), profesor principal e investigador incansable de la Cátedra de Ecología en la Universidad Complutense de Madrid, España. Particularmente, reconocemos su valiosa contribución al conocimiento del funcionamiento de los ecosistemas de las lomas de Atiquipa. Lamentablemente ya ha fallecido, pero dejó una gran escuela de futuros investigadores, tanto en Perú como en España.

Distribución: Los ejemplares estudiados de Liolaemus balagueri fueron encontrados en la zona alta de las lomas de Quilca (640$1060 \mathrm{~m}$ ) en el distrito de Quilca; en Samuel Pastor, en las lomas de La Chira (300-400 m) distrito de Mariscal Cáceres; y en las lomas de Ocoña (600-700 m.), distrito de Ocoña. Todas de las localidades pertenecen a la provincia de
Camaná, departamento de Arequipa, Perú. La zona corresponde a la antigua Cordillera Costera, con altitudes entre los 400-1000 m. (Fig. 4).

Se obtuvieron un total de 21 registros de la especie, los cuales fueron utilizados íntegramente en el modelo. Posterior al análisis de correlación, se determinó que las variables más significativas para la formación del modelo fueron: estacionalidad de la precipitación, radiación solar (14 000-14 500 lux), temperatura en el mes más frío $\left(5-13{ }^{\circ} \mathrm{C}\right)$, precipitación anual (inferior a $10 \mathrm{~mm}$ ) y cobertura vegetal (lomas). Esto concuerda con las características del hábitat en los que se realizaron los registros de la especie. Por ejemplo, la presencia de vegetación de lomas era común en los sitios concurridos por la especie, particularmente los bordes de la vegetación. Este hábitat depende en gran medida de la precipitación de la zona.

Por otro lado, el área estimada para la distribución de estas especies fue $711 \mathrm{~km}^{2}$, políticamente encontrados solamente dentro del departamento de Arequipa entre las provincias de Camaná y Caylloma. La variación 


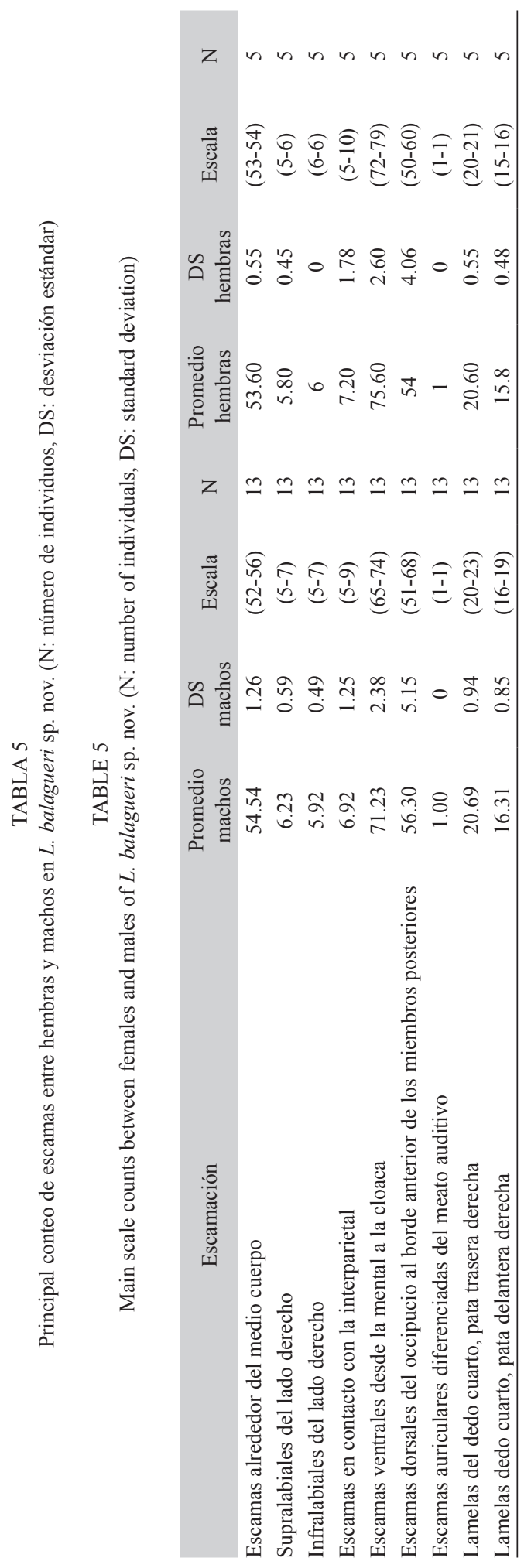

de su altitud se encuentra entre los 300 a 1 $060 \mathrm{~m}$. La distribución más baja fue hacia el norte, próximo al área de Punta La Chira (Fig. 5). Los suelos de estas zonas presentan texturas limosas-arenosas y en algunas zonas hay presencia de rocas. Entre las barreras geográficas identificadas para su ampliación de distribución se encuentran la quebrada del río Quilca hacia el sur y la quebrada del río Ocoña hacia el norte.

Sobre la validación del modelo, según la prueba de AUC (área bajo la curva) se obtuvo un valor de 0.994, es decir, es un modelo mejor que el azar. Asimismo, al realizar una verificación del modelo en campo (la zona de Punta La Chira), se confirmó, mediante una visita de campo, que los sitios marcados con una alta probabilidad de encontrar a la especie presentaban individuos con facilidad.

Historia natural: El hábitat donde se encuentra Liolaemus balagueri es una zona alta de las lomas, con presencia de rocas y de sustrato arenoso-limoso con cobertura rala. La vegetación dominante está dada por pajonales de Cistanthe paniculata, Palaua dissecta, Oziroe biflora, Hierobotana inflata, Wedelia weberbaueri, Haageocereus decumbens y Plantago limensis. Las madrigueras de estos organismos se ubican en el sustrato arenoso-limoso, en el cual excavan pequeñas fosas del tamaño de su cuerpo. Ocasionalmente pueden utilizar madrigueras de alacranes y lagartijas de la especie Phyllodactylus gerrhopygus. Su coloración es críptica con respecto al suelo, lo que les permite camuflarse con facilidad; sin embargo, son fáciles de encontrar en ambientes abiertos, y con escasa cobertura vegetal (Fig. 5).

\section{DISCUSIÓN}

El conocimiento de los reptiles de la costa sur de Perú es aún incipiente. Los listados publicados hasta la fecha de las especies de la familia Liolaemidae para Perú han sufrido de incertidumbres taxonómicas y grandes vacíos geográficos en las colecciones (Carrillo de Espinoza \& Icochea, 1995; Aguilar et al., 2017). 

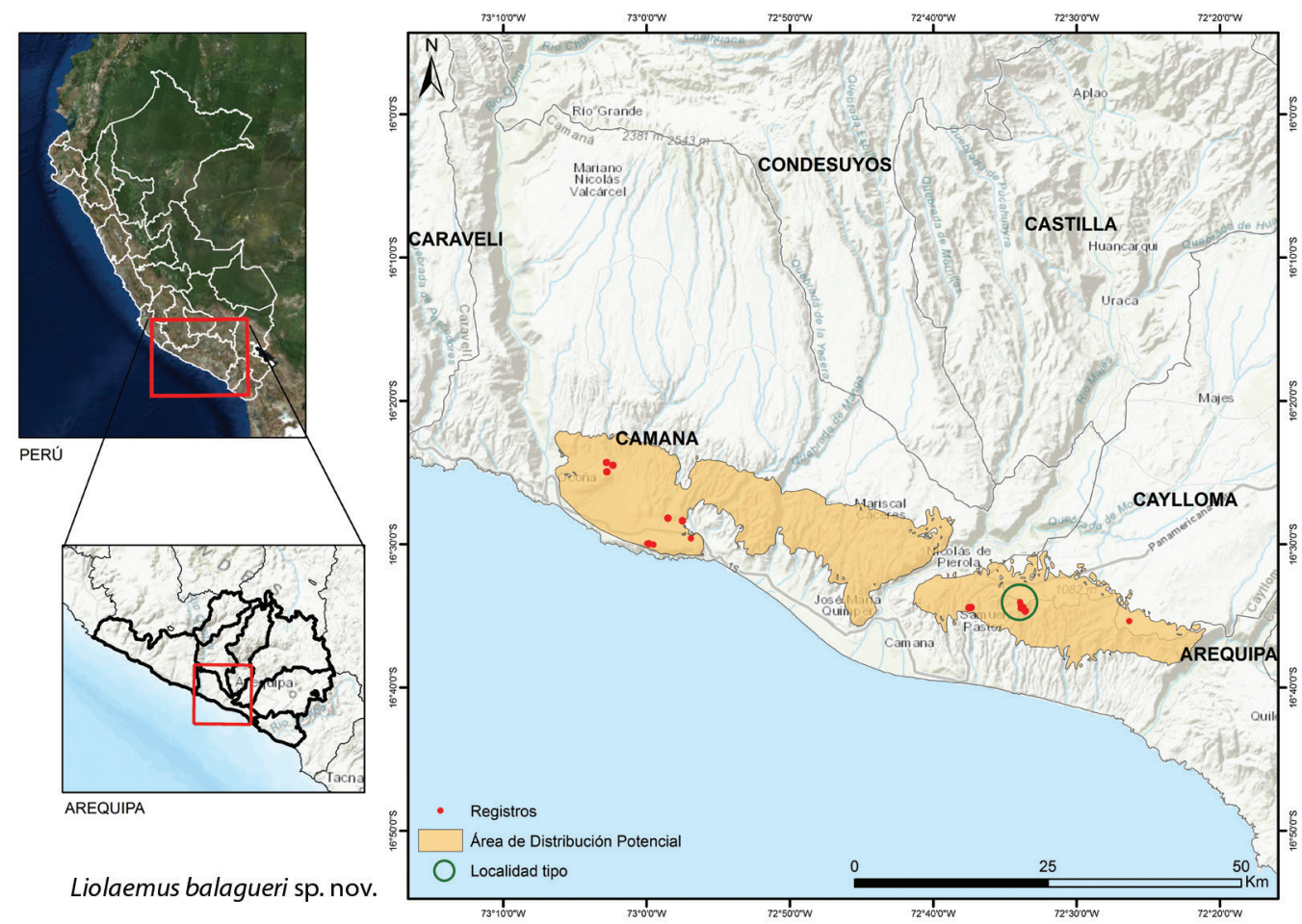

Fig. 4. Distribución potencial de Liolaemus balagueri sp. nov. estimada a partir del análisis de 22 variables ambientales a $100 \mathrm{~m}$ de resolución y con el software Maxent. El círculo corresponde a la localidad tipo.

Fig. 4. Potential distribution of Liolaemus balagueri sp. nov. estimated from the analysis of 22 environmental variables at $100 \mathrm{~m}$ resolution and Maxent software. The circle corresponds to the type locality.

De modo que existen muchas otras aún sin describir (Gutiérrez et al., 2018). Por ello, la descripción de esta nueva especie contribuye al esclarecimiento de la diversidad real de las especies de Liolaemus para este país. Según los resultados, esta nueva especie (Liolaemus balagueri sp nov.) pertenece al grupo de L. montanus (Etheridge, 1995). Dentro de este compendio de organismos, los caracteres morfológicos la acercan a las especies pertenecientes o similares al ex género Phrynosaura (de donde derivan L. audituvelatus, L. insolitus, L. poconchilensis, L. reichei, L. stolzmanni, L. torresi), tal como lo indican los resultados de Etheridge (1995).

Sin embargo, los resultados moleculares presentados en este trabajo indican que L. balagueri sp. nov. no forma parte del mismo grupo monofilético al que pertenecen
L. poconchilensis y L. insolitus. Por lo tanto, el ex género Phrynosaura - ahora sinonimizado con Liolaemus - puede presentarse en distintos nodos del grupo de Liolaemus montanus, como se muestran en los trabajos de Valladares, Etheridge, Schulte, Manríquez \& Spotorno (2002), Aguilar et al. (2017) y Ruiz De Gamboa, Correa, Marambio-Alfaro, Riveros-Riffo, \& Ortiz (2018).

Por otro lado, los resultados del nicho potencial de la nueva especie muestran cierta similitud con lo obtenido en el trabajo de Minoli, Morando \& Ávila (2014), donde se resalta la importancia de la estacionalidad, la precipitación, isotermalidad y la temperatura mínima del mes más frío para el complejo de especies del género Liolaemus, en particular L. fitzingeri. No obstante, las conclusiones obtenidas en este trabajo se distinguen de Aguilar et al. (2013), 


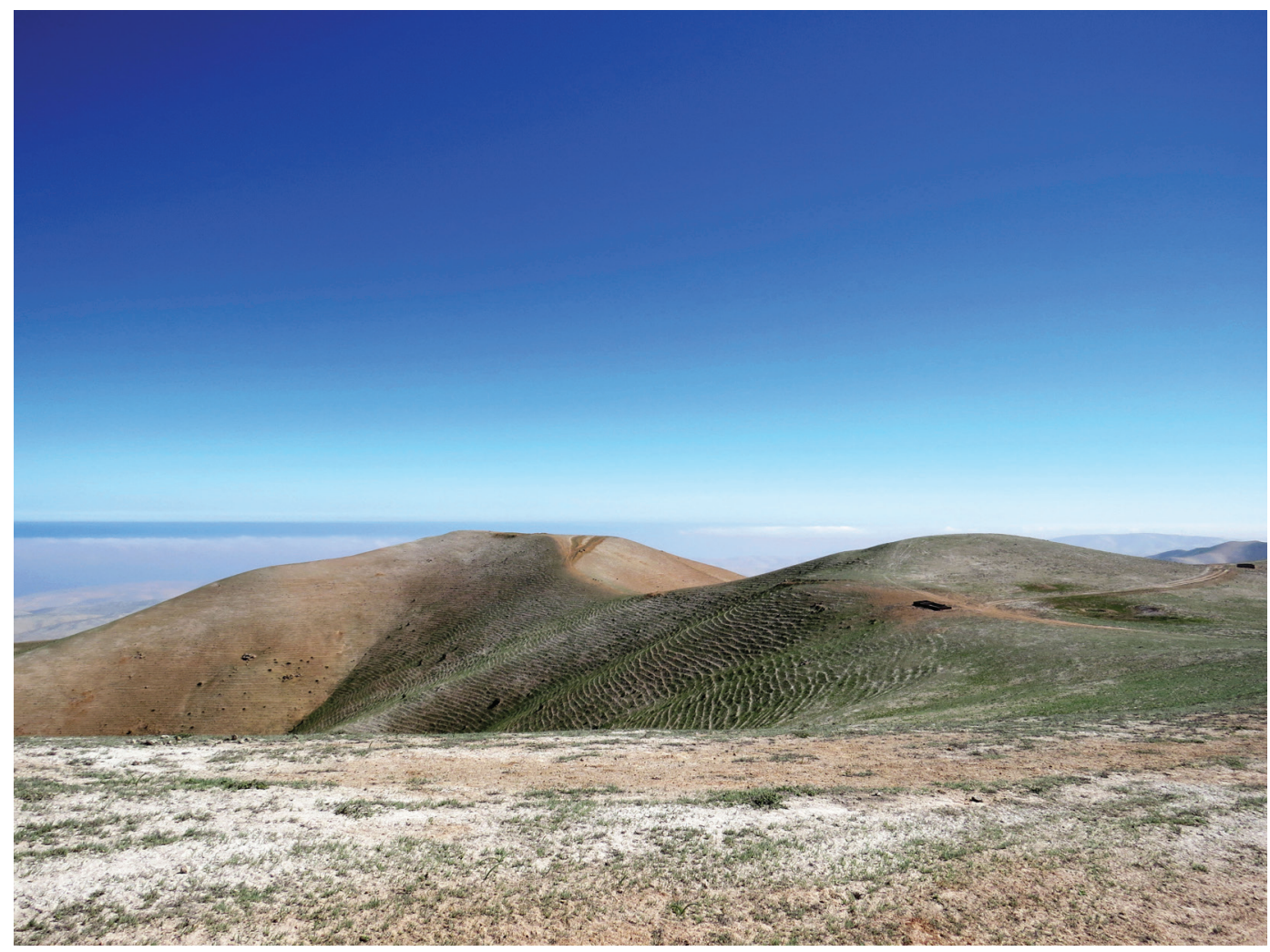

Fig. 5. Hábitat de Liolaemus balagueri sp. nov.

Fig. 5. Habitat of Liolaemus balagueri sp. nov.

donde resaltan la importancia de la precipitación en el periodo más húmedo y la isotermalidad para especies altoandinas del género Liolaemus del complejo de L. walkeri. Bajo la misma línea, Aguilar et al. (2017) propone un modelamiento del nicho potencial para algunas especies del grupo de Liolaemus montanus, el cual no presenta superposición con los nichos potenciales de Liolaemus balagueri sp. nov.

Por último, un punto a considerar es la gran cantidad de poblaciones innominadas que aún se encuentran en las lomas de las costas del centro y el sur de Perú, las cuales están relacionadas o fenéticamente similares a $L$. insolitus. La mayoría de estas poblaciones son asignadas en los museos como L. insolitus; sin embargo, un detallado y exhaustivo análisis morfológico podría evidenciar que son efectivamente poblaciones innominadas y seguramente tienen relación de parentesco entre sí y con las especies descritas de L. montanus. Por ello, podrían ser especies sin describir formalmente para la ciencia (Aguilar et al., 2017). Lo anterior sucede a lo largo de las costas desde Arequipa hasta el sur de Perú. Además, al igual que L. balagueri sp. nov -la cual tiene un endemismo marcadose han encontrado poblaciones cercanas a esta, cuyos datos morfológicos, moleculares (Fig. 3) y de nicho potencial (Fig. 4) pueden evidenciar la existencia de otras especies que deberían describirse formalmente. Por lo tanto, aún queda mucho trabajo taxonómico por hacer en este grupo de lagartijas de Perú.

Declaración de ética: los autores declaran que todos están de acuerdo con esta publicación y que han hecho aportes que justifican su autoría; que no hay conflicto de interés de 
ningún tipo; y que han cumplido con todos los requisitos y procedimientos éticos y legales pertinentes. Todas las fuentes de financiamiento se detallan plena y claramente en la sección de agradecimientos. El respectivo documento legal firmado se encuentra en los archivos de la revista.

\section{AGRADECIMIENTOS}

El presente estudio cuenta con la autorización pertinente de la Administración Técnica Forestal y Fauna Silvestre del Ministerio de Agricultura - Perú. Resolución de Dirección General N¹03-2017-SERFOR/DGGSPFFS $\mathrm{N}^{\circ}$ AUT-IFS-2017-028. Se extiende un fuerte agradecimiento a Johana Quispe, Raquel Ruiz, Miguel Díaz, Adriel Villegas, Anthony Pauca, Jefferson Bedregal, Vanessa Quequejana y Luis Arapa, quienes participaron en las salidas de campo para recolectar y capturar lagartijas. También debemos dar gracias a Evaristo López por el acceso a la colección científica del Museo de Historia Natural de la Universidad Nacional de San Agustín de Arequipa y a la Dra. Ana Lazo por facilitarnos acceso a la información de su proyecto. Este artículo formó parte de la información generada por los proyectos de la Universidad Nacional de San Agustín de Arequipa - UNSA, en el marco del proyecto IBA - 0004-2017-UNSA. Agradecemos además al proyecto de CONICET (Consejo Nacional de Investigaciones Científicas y Técnicas, Argentina) de C. Abdala (PICT 2015-1398).

\section{RESUMEN}

El género Liolaemus presenta una gran diversidad entre los tetrápodos actuales, al punto de corresponder al segundo género con mayor número de especies válidas descritas del infraorden Iguania. En este trabajo, se describe una nueva especie de lagartija arenícola perteneciente al subgénero Eulaemus, grupo de Liolaemus montanus, procedente de las lomas costeras de Quilca, La Chira y Ocoña, todos en la provincia de Camaná, departamento de Arequipa, Perú. Para determinar el estatus taxonómico de esta nueva especie, analizamos los caracteres morfológicos, moleculares y geográficos. Los caracteres morfológicos permitieron la caracterización y diagnóstico de la nueva especie, los moleculares fueron utilizados para realizar una inferencia bayesiana y los geográficos para determinar potenciales áreas de distribución. Este reptil se diferencia de las otras especies del grupo Liolaemus montanus en su tamaño pequeño a mediano, su conjunto de caracteres morfológicos, folidosis y patrón de coloración: es la única especie del género donde los machos tienen un patrón de manchas laterales de forma redondeada con borde oscuro e interior verde desde las axilas hasta la mitad del cuerpo. Del mismo modo, los resultados filogenéticos moleculares realizados con el gen Cyt-b indican que no tiene relación directa con las especies fenéticamente similares descritas para el grupo. Sin embargo, existe una relación con poblaciones geográficamente cercanas que permanecen taxonómicamente innominadas. Finalmente, se determinó que esta lagartija tiene un endemismo muy marcado y sus poblaciones son poco abundantes.

Palabras clave: lagartija, taxonomía, desierto, Camaná, Arequipa.

\section{REFERENCIAS}

Abdala, C. S. (2007). Phylogeny of the boulengeri group (Iguania: Liolaemidae, Liolaemus) based on morphological and molecular characters. Zootaxa, $1538,1-84$.

Abdala, C. S., \& Juaréz-Heredia, V. (2013). Taxonomía y filogenia de un grupo de lagartos amenazados: el grupo de Liolaemus anomalus (Iguania: Liolaemidae). Cuadernos de Herpetología, 27, 109-153.

Abdala, C. S., \& Quinteros, A. (2014). Los últimos 30 años de estudios de la familia de lagartijas más diversa de Argentina. Actualización taxonómica y sistemática de Liolaemidae. Cuadernos de Herpetología, 28, 55-82.

Abdala, C. S., Acosta, J., Cabrera, M., Villavicencio, H., \& Marinero, J. (2009). A new andean Liolaemus of the L. montanus series (Squamata: Iguania: Liolaemidae) from western Argentina. South American Journal of Herpetology, 4, 91-102.

Abdala, V., Abdala, C. S., \& Tulli, M. J. (2006). Three traditional muscular characters in the phylogeny of Liolaemus (Squamata: Tropiduridae) a reappraisal. Zootaxa, 1205, 5568

Aguilar, C., Wood, P., Belk, M., Duff, M., \& Sites, J. (2017). Different roads lead to Rome: Integrative taxonomic approaches leads to the discovery of two lizard lineages in the Liolaemus montanus group (Squamata: Liolaemidae). Biological Journal of the Linnean Society, 120, 448-467.

Aguilar, C., Wood, P., Cusi, J., Guzmán, A., Huari, F., Lundberg, M., Mortensen, E., Ramirez, C., Robles, D., Suarez, J., Ticona, A., Vargas, V., \& Venegas, P. (2013). Integrative taxonomy and preliminary assessment of species limits in the Liolaemus walkeri 
complex (Squamata, Liolaemidae) with descriptions of three new species from Peru. ZooKeys, 364, 47-91.

Carrillo de Espinoza, N., \& Icochea, J. 1995. Lista taxonomica preliminar de los reptiles vivientes del Perú. Publicaciones del Museo de Historia Natural U.N.M.S.M., 47, 1-27.

Cei, J., \& Péfaur, J. (1982). Una nueva especie de Liolaemus (Iguanidae: Squamata): su sistemática, ecología y distribución. Actas del VIII Congreso Latinoamericano de Zoología, 2, 573-586.

Corl, A., Davis, A., Kuchta, S., Comendant, T., \& Sinervo, B. (2010). Alternative mating strategies and the evolution of sexual size dimorphisn in the side-blotched lizard, Uta stansburiana: a population-level comparative analysis. Evolution, 64, 79-96.

Darriba, D., Taboada, G., Doallo, R., \& Posada, D. (2012). jModelTest 2: more models, new heristics and a parallel computing. Naturals Methods, 9, 772.

De Queiroz, K. (1998). The general lineage concept of species, species criteria, and the process of speciation. In D. J. Howard \& S. H. Berlocher (Eds.), Endless Forms: Species and Speciation (pp. 57-75). New York, USA: Oxford University Press.

Edgar, R. (2004). MUSCLE: multiple sequence alignment with high accuracy and high throughput. Nucleic Acids Research, 32, 1792-1707.

Etheridge, R. (1995). Redescription of Ctenoblepharis adspersa Tschudi, 1845, and the Taxonomy of Liolaeminae (Reptilia: Squamata: Tropiduridae). American Museum Novitates, 3142, 1-34.

Fick, S. E., \& Hijmans, R. J. (2017). Worldclim 2: New $1-\mathrm{Km}$ spatial resolution climate surfaces for global land areas. International Journal of Climatology, 25, 1965-1978.

Fielding, A. H., \& Bell, J. F. (1997). A review of methods for the assessment of prediction errors in conservation presence/ absence models. Environmental Conservation, 24, 38-49.

Gutiérrez, R., Chaparro, J. C., Vásquez, M. Y., Quiroz, A. J., Aguilar-Kirigin, A., \& Abdala, C. S. (2018). Una nueva especie de Liolaemus (Iguania: Liolaemidae) de Perú y notas sobre el grupo L. montanus. Cuadernos de Herpetologia, 32(2), 81-99.

Gutiérrez, R., Villegas, L., López, E., \& Quiroz, A. (2010). Anfibios y Reptiles de la Reserva Nacional de Salinas y Aguada Blanca, Perú. En H. Zeballos, J. Ochoa, \& E. López (Eds.), Diversidad biológica de la Reserva Nacional de Salinas y Aguada Blanca (pp. 219-228). Arequipa, Perú: DESCO.

Huelsenbeck, J. P., \& Ronquist, F. (2001). Mr. Bayes: Bayesian inference of phylogenetic tres. Bionformatics, 177, 754-755.
Larson, T. (2015). Systematics of the African River frog genus Amietia (Anura: Pyxicephalidae) from Eastern demographic Republic of Congo (Master's Thesis). University of Texas, Texas, USA.

Laurent, R. (1986). Descripciones de nuevos Iguánidos del género Liolaemus. Acta Zoologica Lilloana, $38,87-105$.

Laurent, R. (1998). New forms of lizards of the Subgenus: Eulaemus of the genus Liolaemus (Reptilia: Squamata: Tropiduridae) from Peru and Northern Chile. Acta Zoologica Lilloana, 44, 1-26.

Lobo, F., Espinoza, R., \& Quinteros, S. (2010). Critical review and systematic discussion of recent classification proposals for liolaemid lizard. Zootaxa, $2549,1-30$

Lobo, F., Espinoza, R. E. (1999). Two new cryptic species of Liolaemus (Iguania: Tropiduridae) from northwestern Argentina: resolution of the purported reproductive bimodality of Liolaemus alticolor. Copeia, 1999, 122-140.

Maddison, W., \& Maddison, D. (2017). Mesquite: a modular system for evolutionary analysis. (Version 3.2). Retrieved from http: //mesquiteproject.org

Minoli, I., Morando, M., \& Ávila, L. J. (2014). Integrative taxonomy in the Liolaemus fitzingerii complex (Squamata: Liolaemini) based on morphological analyses and niche modeling. Zootaxa, 3856(4), 501528. DOI : https://doi.org/10.11646/zootaxa.3856.4.3

Molina, Y., Barreto, G., \& Giraldo, A. (2014). Implementación de la metodología de Anáisis de ADN mitochondrial en Rhinoclemmys nasuta (Testudinae: Geoemydidae). Acta Biológica Colombiana, 19(3), 507-512.

Osorio-Olvera, L. (2016). NicheToolBox R package. Retrieved from https://github.com/luismurao/n ichetoolbox

Phillips, S. J., Anderson, R. P., \& Shapire, R. E. (2006). Maximum entropy modeling of species geographic distributions. Ecological Modelling, 190, 231-259.

Pincheira-Donoso, D., \& Núñez, H. (2005). Las especies chilenas del género Liolaemus Wiegmann, 1834 (Iguania: Tropiduridae: Liolaeminae). Taxonomía, Sistemática y Evolución. Publicación Ocasional del Museo Nacional de Historia Natural Chile, 59, 7-486.

QGIS Development Team. (2017). QGIS Geographic Information System. Open Source Geospatial Foundation Project. Retrieved from http://qgis.osgeo.org

Quinteros, S. (2012). Taxonomy of the Liolaemus alticolor-bibronii group (Iguania: Liolaemidae), with descriptions of two new species. Herpetologica, 68(1), 100-120. 
Quinteros, S. (2013). A morphology-based phylogeny of the Liolaemus alticolor-bibronii group (Iguania: Liolaemidae). Zootaxa, 3670(1), 001-032.

R Core Team (2016). R: A language and environment for statistical computing. R Foundation for Statistical Computing. Vienna, Austria. Retrieved from https:// www.R-project.org

Rambaut, A., Suchard, M., Xie, D., \& Drummond, A. (2014). Tracer v1.6. Retrieved from http://tree.bio. ed.ac.uk/software/tracer

Ruiz de Gamboa, M., Correa, C., Marambio-Alfaro, Y., Riveros-Riffo, E., \& Ortiz, J. C. (2018). Molecular evidence for conspecificity of two desert Liolaemus lizards (Iguania: Liolaemidae). Zootaxa, 4438(2), 283-298.

Schulte, J. A., Macey, J. R., Espinoza, R. E., \& Larson, A. (2000). Phylogenetic relationships in the iguanid lizard genus Liolaemus: multiple origins of viviparous reproduction and evidence for recurring Andean vicariance and dispersal. Biological Journal of the Linnean Society, 69, 75-102.

Uetz, P. (2019). The Reptile Database. Retrieved from http://www.reptile-database.org

Valladares, P. (2004). Nueva especie de lagarto del género Liolaemus (Reptilia: Liolaemidae) del norte de Chile, previamente confundido con Liolaemus (= Phrynosaura) reichei. Cuadernos de Herpetología, 18(1), 43-53.
Valladares, P. (2011). Análisis, síntesis y evaluación de la literatura de lagartos de la Región de Atacama, Chile. Gayana (Concepción), 75(1), 81-98.

Valladares, P., Etheridge, R., Schulte, J. A., Manríquez, G., \& Spotorno, A. (2002). Nueva especie de lagartija del norte de Chile, Liolaemus molinai (Reptilia: Liolaeminae). Revista Chilena de Historia Natural, 75, 473-489.

Valladares-Faúndez, P., Etheridge, R., \& Simón-Abdala, C. (2018). Resurrection and redescription of Liolaemus reichei, proposal of a neotype to stabilize its taxonomy. Revista Mexicana de Biodiversidad, 89, 393-401.

Villegas, L. (1990). Liolaemus (Iguanidae: Squamata) de la provincia de Arequipa: notas sistemáticas y ecológicas (Tesis de Bachillerato). Universidad Nacional de San Agustín. Arequipa, Perú.

Wilcox, T., Zwickl, D., \& Heath, T. (2002). Phylogenetic relationship of the Dwarf Boas and a comparison of Bayesian and bootstrap measures of phylogenetic support. Molecular Phylogenetics and Evolution, 25(2), 361-371.

Zeballos, H., López, E., Villegas, L., Jiménez, P., \& Gutiérrez, R. (2002). Distribución de los Reptiles de Arequipa, Sur del Perú. Revista Cientifica Dilloniana, $11,27-33$. 